figure is applied to the sort of diet eaten in Britain it represents a daily intake of $0.18 \mathrm{~g}$. cyclamate, taking no account of the competition between cyclamates and saccharin, which would reduce it further. Even if half of the sugar intake in Britain was replaced entirely by cyclamate the daily intake would be unlikely to exceed $2 \mathrm{~g}$. and would probably be nearer $1 \mathrm{~g}$. The margin of safety for allowing free use of syclamates seems liberal.

After the publication of the first Government report it was suggested that some human volunteers taking cyclamates had been found to have cyclohexylamine in their urine. The Pharmacology Subcommittee studied the new data in the light of the earlier studies which had suggested that cyclamates were excreted unchanged and that the recovery rate in balance studies was high. Such evidence as existed suggested that the toxicity of cyclohexylamine itself was low. The Subcommittee reported ${ }^{3}$ that had it seen the new work before making its original report it would have insisted on this matter being cleared up ; but that, standing by itself, the new information could not be regarded as sufficient evidence to make it change its recommendation of an acceptable daily intake of $50 \mathrm{mg} . / \mathrm{kg}$. body weight.

There can be little doubt that any risk that cyclamates pose to human health has had very thorough consideration. The body of consistent experimental results referred to in the first report must be considered as without challenge at present. Any scientific conclusion reached at a single point of time is vulnerable to the future; but this will always be so. The evidence at present, however, supports the Minister's conclusions that statutory restriction of the use of cyclamates could not be justified.

\section{Congenital Heart Disease with Pulmonary Hypertension and a Reversed Shunt}

One of the steps in arriving logically at a clinical diagnosis in congenital heart disease is the recognition of a group of patients with pulmonary hypertension and a reversed shunt. These patients have a delayed onset of cyanosis, as opposed to patients with Fallot's tetralogy, in whom cyanosis is present from birth. The signs of pulmonary hypertension will usually be obvious clinically: a sustained lift in the left parasternal area due to right ventricular hypertrophy and a loud ringing pulmonary second sound. The electrocardiogram will confirm the presence of right ventricular hypertrophy. The next step in diagnosis is to differentiate the main types of congenital defect that can give rise to this syndrome. The three common conditions are an atrial septal defect, a ventricular septal defect, and a patent ductus arteriosus. Normally in these conditions the shunt is from left to right, but in certain circumstances changes in the peripheral pulmonary vasculature may cause pulmonary hypertension of a degree sufficient to reverse the direction of the shunt. Clinical differentiation of these three congenital defects when associated with pulmonary hypertension is not always easy, since with reversal of the shunt the classical type of murmur associated with each disappears. Some help may be obtained from the observation that early reversal of the shunt in the first decade suggests the defect is a ventri-

' Rees, R. S. O., and Jefferson, K. E., Clin. Radiol., 1967, 18, 366.
Wood, P., Brit. med. Y., 1958. 2, 701. cular septal defect, while it is unusual for the shunt to reverse in atrial septal defect until about the third decade.

Radiology of the heart offers a further ancillary aid to diagnosis, and recently R. S. O. Rees and K. E. Jefferson ${ }^{1}$ have concluded that the site of the shunt can generally be predicted by assessment of the cardiac silhouette and of the pulmonary vascular pattern. They found in a series of 81 patients with the syndrome of congenital heart disease complicated by pulmonary hypertension and a reversed shunt (Eisenmenger syndrome ${ }^{2}$ ) that the largest hearts and biggest proximal pulmonary arteries were associated with atrial septal defects. Patent ductus was characterized by a flat aortic knuckle and gross enlargement of the main pulmonary artery. The cardiac silhouette and pulmonary vascular pattern were often nearly normal in ventricular septal defect. Plain radiological findings in this condition, however, can point only to one diagnosis being more likely than another even when all the other clinical features of the case are taken into account. Nor should it be forgotten that in this syndrome more than one congenital defect may be present, such as patent ductus in association with a ventricular septal defect. Cardiac catheterization and angiocardiography are therefore usually required for final diagnosis, and at the same time the nature of the anatomical and haemodynamic abnormalities can be clearly defined.

\section{Nursing the Mentally Retarded}

The Earlswood Asylum in Surrey was opened by the Prince Consort in 1855 . At that time the legal distinction between the mentally ill and the mentally retarded was not very clear, and the Lunatic Asylum Act of 1853 stated that the word "lunatic" included idiots. But the Metropolitan Asylums Board created in 1867 had the task of transferring idiots and imbeciles from Metropolitan workhouses and lunatic asylum to the Caterham, Leavesden, and Hampstead Idiot Asylums Like other asylums those providing for the mentally retarded have become hospitals and are staffed by nurses and doctors The Earlswood Asylum is now the Royal Earlswood Hospital Darenth Training Colony, set up in 1875, is now Darenth Park and is classed as a hospital. In the early years of this century and in the period between the wars with mass unemployment the wisdom of providing large isolated units for the mentally retarded was little questioned and there was agitation for more places. In 196114,576 patients in psychiatric hospitals were classed as subnormal and 46,669 as severely subnormal. The corresponding figures for 196.5 were 15,703 and 48,803 . The numbers therefore appear to be continuing to rise, as they have done fairly steadily since the end of the first world war, when the effect of the Menta Deficiency Act and provisions created in connexion with it began to be felt.

O'Connor, N., and Tizard, J., The Social Problem of Mental Deficiency, 1956. London.

- Hilliard, L. T., Brit. med. f., 1954, 1, 1372.

Report of a Working Party on Subnormality, Bull. Brit. psychol. Soc. 1963, 53, 37.

Tizard, J., and Grad, J. C., The Mentally Handicapped and The: Families : A Social Survey, 1961. London

- McKeown, T., and Leck, I., Brit. med. F., 1967, 3, 573.

orking Party of the Royal College of Nursing, The Function, Scope and Training of Nurses in England and Wales for the Mentally Subnormal. 1967. London.

Annual Report of the Ministry of Health for the Year 1965, 1966 London.

Tizard, J., Community Services for the Mentally Handicapped, 1964.
London. 
The work of N. O'Connor and J. Tizard ${ }^{1}$ at Darenth Park suggested that there were large numbers of people detained in mental deficiency hospitals who could in the changed postwar economic climate be earning their living in open competition-and sometimes earning more than the nurses employed to look after them. Their findings have been supported by others, ${ }^{2}$ and recent surveys ${ }^{3}$ suggest that there are still in hospitals for the mentally subnormal considerable numbers of people who in respect of intelligence alone have sufficient ability to maintain themselves in the general community. In regard to the more severely mentally handicapped, however, Tizard and J. C. Grad 4 found that two-thirds of idiots and imbeciles in hospital had a major additional disability.

It has been suggested recently ${ }^{5}$ that a considerable proportion of mentally retarded patients at present in hospital need not be there, and that they should be transferred to local authority care. But this carries the implication that staff would still need to be employed to look after them. And indeed one reason why many very mentally handicapped patients need a hospital type of care is the presence of multiple handicap and the need for physical nursing.

A report ${ }^{6}$ recently issued by the Royal College of Nursing lays stress on the role of the nurse in meeting the educational and social needs of the mentally subnormal. The report claims that with the gradual introduction of specialized staff into the team the nurse has tended to lose the opportunity to organize a therapeutic regimen. In 1965 some 10,000 nurses were employed in this work whole-time and about 3,300 part-time in England and Wales. ${ }^{7}$ Half the full-time men and a quarter of the full-time women are trained nurses. The Royal College inquiry showed there were also 1,844 student nurses in this branch in England and Wales, with $98 \%$ from the U.K. and Eire in the North and $35 \%$ in the South-east. The report calls for improvement in the status and training of the nurse in this branch of the profession and rejects-though perhaps questionably-an amalgamation of the training of these nurses with that of nurses for mental illness. Tizard ${ }^{8}$ has suggested alternative forms of provision for those mentally retarded patients who need residential care. But there will for long be a continuing need for a body of dedicated men and women to care for the mentally handicapped. Moreover, there should be a further review of the professional training open to them.

\section{Hypermobile Joints}

Generalized laxity of articular ligaments is a feature of such inherited diseases of connective tissue as Marfan's syndrome, the Ehlers-Danlos syndrome, and osteogenesis imperfecta. ${ }^{1}$ It is also seen in rare metabolic conditions such as homocystinuria $^{2}$ and hyperlysinaemia. ${ }^{3}$ Acquired hypermobility may follow inflammatory polyarthritis, including rheumatoid arthritis, and it is a characteristic and prominent abnormality in neuropathic joint disease. Joints which are unduly lax may be injured by minor degrees of trauma which would be harmless to joints of normal stability, and are therefore liable to develop traumatic synovitis, with serous or haemorrhagic effusions and later secondary osteoarthrosis.

Generalized laxity of joints also occurs as an isolated finding in otherwise normal people, often with a familial incidence. ${ }^{s}$ Thus in a study of 435 adult orthopaedic outpatients it was found that $4 \%$ showed hypermobility of three or more pairs of joints. ${ }^{\circ}$ Again, C. Carter and J. Wilkinson found hypermobility of four or more pairs of joints in $7 \%$ of 285 schoolchildren.' Joint laxity of this type predisposes to dislocation and deformity of the hip, patella, shoulder, and other joints. ${ }^{8-10}$

Recently J. A. Kirk, B. M. Ansell, and E. G. L. Bywaters ${ }^{11}$ re-examined 24 patients whose musculoskeletal complaints had originally been attributed by various examining physicians to generalized joint laxity. In three-quarters of these patients symptoms had begun before the age of 15 ; the sex incidence was equal in the children, but all the adults were femalepossibly by chance. The main complaints were of joint pain and effusion, most often in the knees. Though symptoms predominated in joints of the lower limbs, hypermobility was most easily detected in movements of the hands and wrists. One-third of the patients considered themselves to be "double-jointed."

The clinical picture in these cases was very variable, ranging from children with relatively transient pain in muscles or joints to adults with long-standing pain and effusion in the joints leading to early degenerative arthritis. The patients were carefully examined for signs of hereditary disorders of connective tissue, such as hyperelastic skin, easy bruising, high palate, or abnormalities of body proportion. Such examination was essentially negative, nor was there any evidence of inflammatory synovitis: the sedimentation rate was normal, and needle biopsy of a joint carried out on one patient showed normal synovium. Nine first-degree relatives of these patients were also examined and were found to show evidence of joint hypermobility, two of them having symptoms attributable to it.

The question arises whether the condition represents one extreme of a normal variation in joint mobility, or whether it is to be regarded as an incomplete form of such disorders as the Marfan or the Ehlers-Danlos syndromes. Since we lack any firm biochemical criteria for the diagnosis of these diseases it is not yet possible to be certain on this point, but the absence of any other stigmata among patients or their relatives is against the second view. Normal people vary widely with respect to joint mobility, ${ }^{12}$ and it seems unlikely that there is anything more than a quantitative distinction to be drawn between normal persons and patients who develop symptoms from their hypermobile joints.

The importance of this syndrome lies in its recognition. It is not uncommon to find that such patients have had numerous but uncertain diagnoses attached to their complaint, and they are consequently relieved to receive a confident explanation of their problem. Management is largely confined to avoidance of any activity which brings on symptoms in the joints, together with general exercises, such as swimming, directed towards developing musculature. Though little else can be offered by way of treatment, it is at least reassuring for the patient to know that the condition does not carry the serious prognosis which may apply to some other forms of joint disease.

\footnotetext{
McKusick, V. A., Heritable Disorders of Connective Tissue, 1966, 3rd ed. St. Louis.

Schimke, R. N., McKusick V. A., Huang, T., and Pollack, A. D., J. Amer. med. Ass., 1965, 193, 711.

Ghadimi, H., Binnington, V. I., and Pecora, P., New Engl. 7. Med., $1965,273,723$.

Key, J. A., ₹. Awer med Ass., 1927, 88, 1710.

Sturkie, P. D. F. Hereu., 1941, 32, 232

- Sutro, C. J., Surgcrv, 1947, 21, 67.

' Carter, C and Wilkinson, J.. \%. Bone ft Surg., 1964, 46B, 40

- Massie, W. K. and Howorth. M B., J. Bone of Surz., 1951, 33A, 190.

9 Hass, J., and Hass, R., \%. Bons it Surg., 1958, 40A, 663.

1. Carter, C., and Sweetnam. R.. 7. Bone ft Surg., 1960, 42B, 721.

1 Kirk. J. A., Ansell, B. M., and Bywaters, E. G. L., Ann. rheum. Dis., $1967,26,419$.

Scott, J. T., Ann. rheum. Dis., 1960, 19, 361.
} 